\title{
Clinical diagnostics and therapy monitoring in the congenital disorders of glycosylation
}

\author{
Monique Van Scherpenzeel $^{1,2} \cdot$ Esther Willems ${ }^{1,2} \cdot$ Dirk J. Lefeber $^{1,2}$
}

Received: 28 August 2015 /Revised: 3 November 2015 / Accepted: 18 November 2015 /Published online: 7 January 2016

(C) The Author(s) 2016. This article is published with open access at Springerlink.com

from genetic disease, and review the increasing opportunities of mass spectrometry to analyze protein glycosylation in the clinical diagnostic setting. Furthermore, we will discuss the possibilities to expand current CDG diagnostics and how this can be used to approach glycoprotein biomarkers for more common diseases.

Keywords Congenital disorders of glycosylation . Glycomics · Protein-specific glycosylation · Transferrin

$\begin{array}{ll}\text { Abbreviations } \\ \text { 2DE } & \text { 2D-electrophoresis } \\ \text { apoC-III } & \text { apolipoprotein CIII } \\ \text { CA125 } & \text { cancer antigen 125 } \\ \text { CA15-3 } & \text { cancer antigen 15-3 } \\ \text { CA19-9 } & \text { carbohydrate antigen 19-9 } \\ \text { CA27-29 } & \text { cancer antigen 27-29 } \\ \text { CD24 } & \text { cluster of differentiation 24 or heat stable antigen } \\ & \text { CD24 (HSA) } \\ \text { CD59 } & \text { MAC-inhibitory protein (MAC-IP) } \\ \text { cdg } & \text { Congenital Disorders of Glycosylation } \\ \text { CDG-I } & \text { Congenital Disorders of Glycosylation type I } \\ \text { CDG-II } & \text { Congenital Disorders of Glycosylation type II } \\ \text { CID } & \text { collision induced energy } \\ \text { COPD } & \text { Chronic obstructive pulmonary disease } \\ \text { CRC } & \text { Colorectal cancer } \\ \text { ELISA } & \text { Enzyme Linked Immunosorbent Assay } \\ \text { ELLA } & \text { enzyme-linked lectin assay } \\ \text { ETD } & \text { electron transfer dissociation } \\ \text { FACS } & \text { fluorescence activated cell sorting } \\ \text { FDA } & \text { US Food and Drug Administration } \\ \text { FLISA } & \text { Lectin-Fluorophore-linked Immunosorbent } \\ \text { FRU } & \text { Assay } \\ \text { FUC } & \text { fructose } \\ \end{array}$




\begin{tabular}{|c|c|}
\hline GAL & galactose \\
\hline GDP & guanosine diphosphate \\
\hline GFPT1 & Glutamine-Fructose-6-Phosphate Transaminase 1 \\
\hline GLC & glucose \\
\hline GNE & $\begin{array}{l}\text { UDP-N-acetylglucosamine 2-epimerase/N- } \\
\text { acetylmannosamine kinase }\end{array}$ \\
\hline gpi & glycosylphosphatidylinositol \\
\hline $\mathrm{HCC}$ & Hepatocellular carcinoma \\
\hline hCG & Human chorionic gonadotrophin \\
\hline HILIC & Hydrophilic Interaction LIquid Chromatography \\
\hline ICAM-1 & intercellular cell adhesion molecule 1 \\
\hline IEF & Iso Electric Focusing \\
\hline $\operatorname{IgG}$ & Immunoglobulin $\mathrm{G}$ \\
\hline LAD-II & leukocyte adhesion deficiency II \\
\hline LAMP-2 & lysosome-associated membrane protein 2 \\
\hline $\mathrm{LC}$ & Liquid Chromatography \\
\hline LC-MS & Liquid Chromatography - mass spectrometry \\
\hline LLO & Lipid linked oligosaccharide \\
\hline MAC & membrane attack complex \\
\hline MALDI- & matrix assisted laser desorption ionisation - \\
\hline TOF & Time-of-Flight \\
\hline MAN & Mannose \\
\hline MRM & multiple reaction monitoring \\
\hline MUC16 & $\begin{array}{l}\text { mucin } 16 \text { or ovarian cancer-related tumor marker } \\
\text { CA125 }\end{array}$ \\
\hline NP- & normal phase - high pressure liquid \\
\hline HPLC & chromatography \\
\hline PSA & prostate specific antigen \\
\hline QTOF & quadrupole time of flight \\
\hline SRM & single reaction monitoring \\
\hline$s L e^{X}$ & Sialyl Lewis X structures \\
\hline$s L e^{a}$ & Sialyl Lewis A structures \\
\hline tief & transferrin isoelectric focusing \\
\hline UDP & uridine diphosphate \\
\hline $\begin{array}{l}\text { UPLC- } \\
\text { MS }\end{array}$ & $\begin{array}{l}\text { ultra high pressure liquid chromatography- mass } \\
\text { spectrometry }\end{array}$ \\
\hline WAX- & weak anion exchange high performance liquid \\
\hline
\end{tabular}

\section{List of human genes}

ALG13 subunit of UDP- $N$-acetylglucosamine transferase complex

ALG14 subunit of UDP- $N$-acetylglucosamine transferase complex

ALG1 mannosyltransferase 1

ALG8 glucosyltransferase 2

DOLK dolichol kinase

GCS1 mannosyl-oligosaccharide glucosidase

MAN1B1 alpha-1,2-mannosidase

MPI mannose phosphate isomerase

PGM1 phosphoglucomutase 1

PGM3 phosphoglucomutase 3
PIGM glycosylphosphatidylinositol

PMI Phosphomannose isomerase

PMM2 phosphomannomutase

SLC35A2 UDP-galactose transporter

SLC35A3 UDP- $N$-acetylglucosamine transporter

SLC35C1 GDP-fucose transmembrane transporter

TUSC3 Oligosaccharyltransferase TUSC3 subunit

VPS13B Vacuolar Protein Sorting 13 Homolog B

\section{Contents}

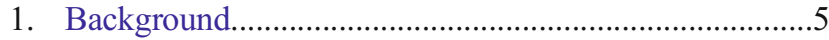

2. CDG diagnostics and gene identification..........................

3. Therapy development for CDG.......................................

4. Novel glycoprotein biomarkers for CDG.......................13

4.1. The need for glycoprotein biomarkers beyond transferrin

4.2. Potential glycoprotein biomarkers for diagnostic application in CDG

5. Mass spectrometry in glycoprotein analysis..................17

5.1. Glycoprotein biomarker discovery.

5.2. Glycoprotein biomarker application in clinical

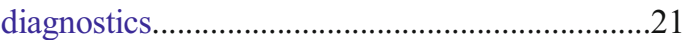

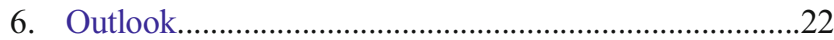

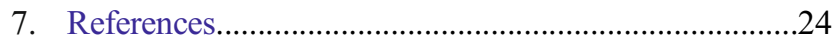

\section{Background}

Protein glycosylation is a non-template driven, dynamic, and post-translational modification on top of protein synthesis. Glycans have important functions in many biological processes such as protein folding, clearance and cell-cell interactions. Considering glycosylation to be the final and top level after DNA and protein synthesis, glycosylation is the most informative level, being a product of the genome and environmental factors together. Therefore, the use of glycomics methods to read this information holds enormous potential for the development of unique biomarkers for human diseases. In several genetic and chronic diseases, like cancer [1-3], inflammation [4], Alzheimer's disease [5], diabetes [6, 7] and metabolic disorders [8], glycosylation of proteins is changed dramatically. Analysis of glycosylation has the benefit that it provides information about the current status of the patient, which enables early diagnosis of disease onset and therapy monitoring.

Still major technological advances have to be made before glycoprotein biomarkers can be widely used in clinical 
diagnostics. In addition, clinical validation of potential biomarkers is equally important as well as the knowledge of how to interpret glycosylation abnormalities in the context of a certain disease. Important lessons can be learned by a comparison with a group of well-defined genetic defects, the Congenital Disorders of Glycosylation (CDG). CDG encompasses a group of inherited diseases with abnormal glycan metabolism. According to current nomenclature [9], they are divided into four different biochemical groups, comprising errors in protein $\mathrm{N}$-linked glycosylation, protein O-linked glycosylation, glycolipid and GPI anchor glycosylation, and a group with defects in multiple glycosylation pathways [10]. Over 100 human genetic disorders have been associated with abnormal glycosylation [8, 11], of which at least 50 types are linked to deficient $\mathrm{N}$-glycosylation of serum transferrin, historically referred to as CDG [12]. Because the defective genes are involved in a variety of functionally diverse metabolic pathways, the clinical presentation of CDG subtypes is highly heterogeneous. Clinical phenotypes range from mild to severe and involve multiple or only single affected organs. Examples of clinical symptoms include intellectual disability, seizures, muscle dystrophy, skeletal dysplasia, dysmorphic features, growth retardation, hematological and endocrine abnormalities, which show the widespread requirement of proper glycosylation for the human system $[13,14]$. In line with these diverse clinical symptoms, diagnosis can be very challenging. Currently, only transferrin glycosylation analysis is widely used in clinical diagnostics for CDG.

Advanced mass spectrometry (MS) was introduced in CDG research to analyze released glycans from serum proteins [15-17] to gain more detailed insights in the glycan structural abnormalities. The growing contribution of mass spectrometry in the diagnosis of CDG is outlined in a recent review by Sturiale et al. [18]. Intact glycoprotein analysis of transferrin followed after the rapid development of mass spectrometry techniques and has now been added to routine diagnosis [19] and recently to therapy monitoring of CDG [20]. This method for protein-specific analysis has allowed high-resolution annotation of glycan structures, thereby revealing unique glycosylation profiles for specific genetic defects. This shows the potential to include mass spectrometry in specialized diagnostic laboratories and has already improved the diagnostic process by significantly shortening the time to reach a diagnosis.

It can be predicted that more glycosylation disorders will be reported in the near future since at least $2 \%$ of the human genes encodes for proteins involved in glycan biosynthesis and recognition [8], and 5-10\% for proteins involved in Golgi homeostasis with a potential indirect effect on glycan metabolism. In addition, the wide-spread diagnostic application of next-generation sequencing is increasing the speed of CDG gene discovery [21]. The complexity of different glycosylation pathways, and the existence of tissue- and proteinspecific glycosylation, indicates that the current use of transferrin as diagnostic marker is only a mere start to apply methods for glycoprotein analysis in a clinical diagnostic setting. In addition, the coming decade will show a merging of monogenic defects with genetic predisposition in more common diseases with abnormal protein glycosylation. Thus, there is a clear need to develop additional glycoprotein biomarkers to grasp the full scope of glycosylation defects in a diagnostic setting, and to learn how to interpret glycosylation abnormalities in the context of more common diseases.

Here, we will first describe the current state of diagnostics and gene identification for CDG. Secondly, we will discuss the potential use of existing plasma glycoprotein biomarkers, and finish with a look to the future in suitable mass spectrometry approaches for analysis of glycoproteins in clinical diagnostics.

\section{CDG diagnostics and gene identification}

Defects in the N-glycosylation pathway are the best studied types of CDG. They are localized to the cytoplasm and the endoplasmic reticulum (ER) in CDG-I or to the cytoplasm and Golgi apparatus in CDG-II [22]. CDG-I defects are characterized by unoccupied glycosylation sites on proteins, thus lacking complete N-glycans, whereas CDG-II defects show immature, truncated glycans. Currently, the first line screening for these CDG subgroups in the majority of metabolic laboratories world-wide is based on the analysis of transferrin $\mathrm{N}$ glycosylation by isoelectric focusing (TIEF), first introduced in 1984 by Jaeken et al. [23], by HPLC [24] or by capillary electrophoresis (CE) [25, 26]. These techniques allow separation of transferrin isoforms on basis of charge state determined by the number of terminal sialic acid residues (see Fig. 1). Normal plasma transferrin contains two complex type Nglycans with in total four terminal sialic acid residues as most dominant species (lanes 1 and 3). CDG patients show a decrease of this tetrasialo transferrin isoform and an increase of lower sialylated species. Abnormal profiles are classified as either CDG-I or CDG-II, depending on an isolated increase of asialo- and disialotransferrin bands (lane 2, CDG-I) or an additional increase of monosialo- and trisialotransferrin bands (lanes 4, 5 and 6, CDG-II), respectively [27]. Diagnostic interpretation of abnormal profiles can be complicated by the presence of transferrin polymorphisms that co-migrate with abnormally glycosylated transferrin isoforms [28, 29] (example in lane 8, Fig. 1). Treatment of serum transferrin (in vitro) with neuraminidase (sialidase), or alternatively analysis of parental plasma samples, is used to confirm or exclude a transferrin polymorphism [30] (lanes 6 to 9). Secondary causes of abnormal transferrin glycosylation are for example alcohol abuse, resulting in CDG-I profiles, the presence of sialidase in the plasma, or severe liver disease, both resulting in CDG-II profiles. In the majority of cases, CDG-I and -II profiles can be clearly discriminated. However, very mild CDG-I profiles can 

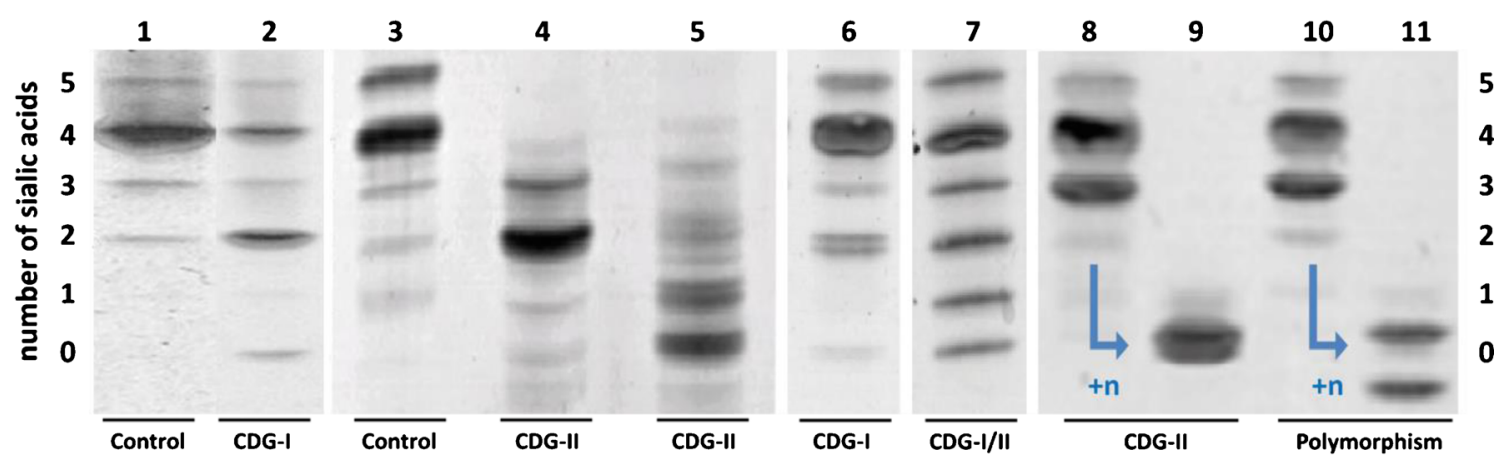
would be applicable to other CDG types as well, but are still under development. Several challenges have to be overcome, like the lack of appropriate model systems, high costs, small number of patients and the limited bioavailability of the drugs to reach their target, especially in regard to pass the bloodbrain-barrier [44]. Only in four CDG subtypes, namely MPICDG, PGM1-CDG, SLC35C1-CDG and PIGM-CDG, a mechanism-based treatment has been applied [20, 45-48].

MPI-CDG is caused by a mutation in the cytosolic enzyme phosphomannose isomerase (MPI). The enzyme catalyzes the conversion of fructose-6-phosphate to mannose-6-phosphate [49], and therefore the disease is characterized by decreased mannose-6-phosphate. Mannose supplementation increased the mannose-6-phosphate levels and improved the clinical features in patients [45]. Despite mannose therapy, patients can develop progressive liver failure at a later stage of the disease. One first patient was successfully treated by liver transplantation, resulting in immediate recovery of most severe clinical symptoms [50]. As expected in view of the hepatic origin of transferrin, intact transferrin glycosylation profiles completely normalized after the transplantation. However, the disease status in other organs cannot be followed adequately by analysis of transferrin alone. This clearly shows the need for additional biomarkers for CDG therapy monitoring, including glycoproteins that are synthesized by other tissues and cell types.

PGM1-CDG is caused by a mutation in the phosphoglucomutase 1 enzyme (PGM1). The enzyme catalyzes the interconversion of glucose-6-phosphate and glucose-1-phosphate [51]. The disease was identified by a highly characteristic transferrin glycosylation profile with high-resolution mass spectrometry, which showed a combination of CDG-I and CDG-II. The spectra showed truncated glycans lacking galactose. Based on the spectra and known metabolic pathways, supplementation of patients with galactose resulted in almost complete normalization of transferrin glycosylation [20] (Fig. 2). The normalization of the truncated glycans upon galactose treatment can be explained based on known metabolic pathways. However, the normalization of the complete glycans (CDG-I) cannot be fully explained. More detailed insight into the dynamics and regulation of sugar metabolism, and its link with protein glycosylation, would help us to better understand the glycosylation machinery, further optimize therapy and develop new therapies for other CDG patients. In addition, monitoring of the glycosylation of additional proteins is required to learn if other tissues apart from liver respond equally well to galactose treatment.

SLC35C1-CDG is caused by a mutation in the GDP-fucose transporter in the Golgi-membrane, resulting in hypofucosylation of N-glycopeptides [52]. Patients typically lack sialyl-Lewis X (sLex) structures on the cell surface of neutrophils, which is required for their rolling on endothelial cells before extravasation [53]. This CDG type is therefore also known as leukocyte adhesion deficiency II (LAD II) and leads to infectious complications.
Depending on the nature of the mutation, some patients respond to L-fucose application [46, 54]. However, no proper glycoprotein marker is currently available to monitor therapy response and disease progression.

PIGM-CDG is a defect in GPI-anchor biosynthesis and is caused by a mutation in the glycosylphosphatidylinositol glycan (class M) (PIGM) promoter. PIGM transfers the first mannose to the GPI anchor at the luminal side of the endoplasmic reticulum [55]. Mutation in the promoter causes histone hypoacetylation, resulting in defective GPI anchored proteins on blood cells [47]. A patient was therefore treated with sodium phenylbutyrate, which is a histone deacetylase inhibitor. This increased PIGM transcription, resulting in improved GPI anchored glycoproteins: CD59 (MAC-inhibitory protein) on erythrocytes and CD59 and CD24 (heat stable antigen) on granulocytes (FACS analysis) [55]. Clinically, the patient improved and was able to walk again and had no more seizures [48].

Currently, CDG therapy monitoring is mainly based on clinical features, transferrin analysis or flow cytometry of several glycoprotein surface markers on blood cells. The main advantage of using transferrin as a biomarker for CDG is its high abundance in blood, allowing fast, detailed and sensitive detection of $\mathrm{N}$-glycosylation in small sample volumes. Also for treatment of fructosemia, a common secondary cause of CDG, the loss of intact glycans can be monitored sensitively by high resolution mass spectrometry of transferrin [31]. However, therapy monitoring in clinical diagnostics is very limited with the analysis of transferrin, and additional biomarkers are essential for the development and monitoring of new and current therapies.

\section{Novel glycoprotein biomarkers for CDG}

\section{The need for glycoprotein biomarkers beyond transferrin}

Although transferrin is a very useful diagnostic biomarker for most CDG types with deficient N-glycosylation, several defects in the N-glycosylation pathway are known with a normal transferrin profile. These include both CDG-I subtypes (TUSC3-CDG, ALG13-CDG, ALG14-CDG), Golgi glycosylation defects (GCS1-CDG, SLC35A3-CDG and SLC35C1-CDG), as well as defects in sugar metabolism (GNE, PGM3 and GFPT1). The growing list of these type of defects with normal transferrin glycosylation indicates that additional proteins have to be included for correct diagnosis. Since glycans can be expressed in a tissue-specific way [56-58], defects in their synthesis will be missed when analyzing only hepatocyte-derived transferrin. Furthermore, analysis of defects in the synthesis of glycan structures not or hardly present on transferrin (such as fucose in SLC35C1CDG), will require inclusion of additional proteins. Additionally, recent studies indicate the existence of 
Fig. 2 Effects of Dietary Galactose on Glycosylation. High resolution mass spectrometry showing glycan structures of transferrin before (a) and after (b) 2 weeks intake of supplementary galactose and corresponding patterns of transferrin isoelectric focusing (IEF). The protein backbone is symbolized by a brown horizontal line. The unoccupied positions are indicated by open arrows (Љ) and define the CDG-I-component of this phenotype. The yellow arrow $(\vec{b})$ demonstrates the absence of galactose on one of the truncated glycans, which define the CDG type-II component. The number of sialic acids is indicated above each structure, and the insets at the right show respective IEF results

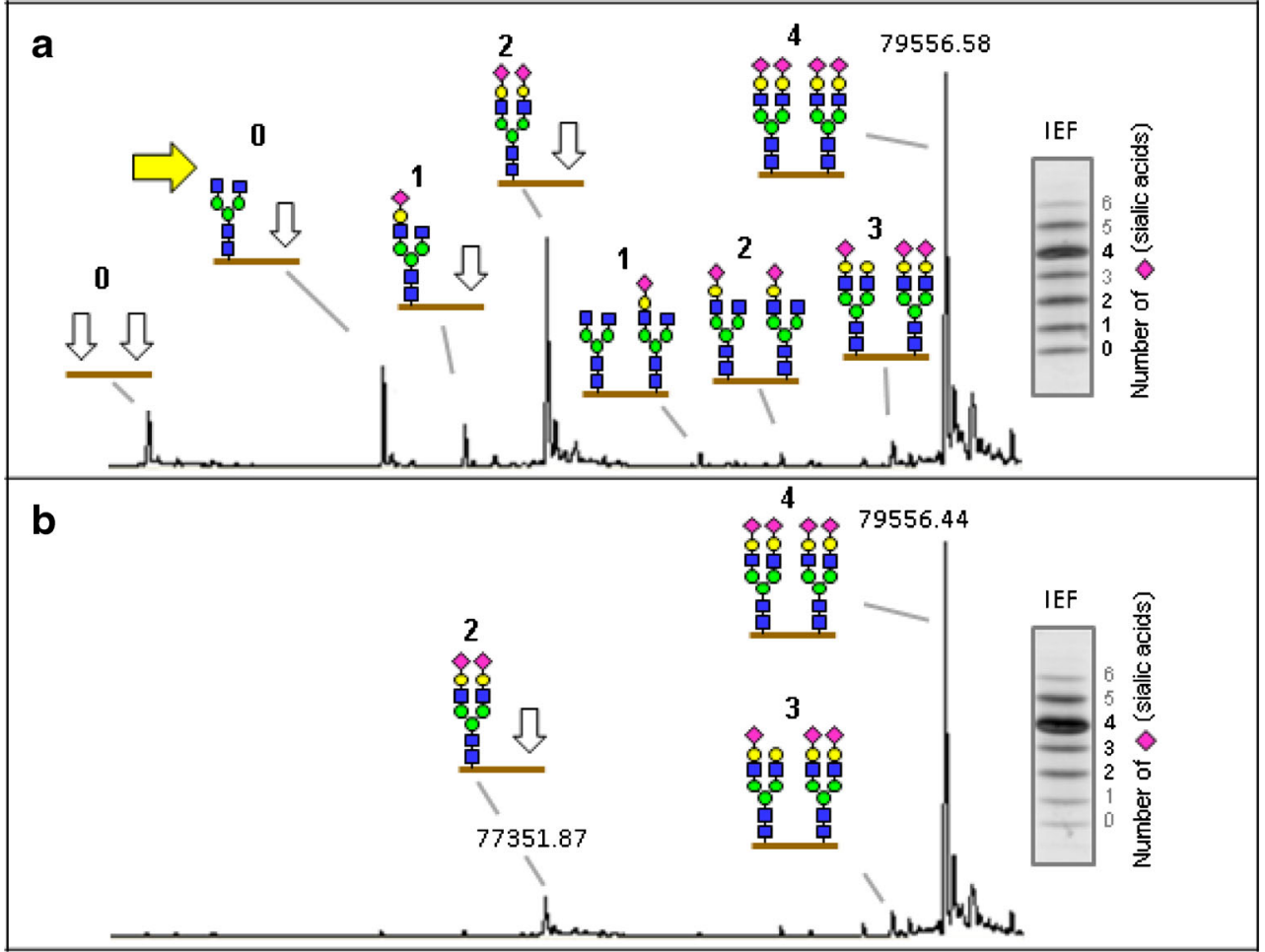

regulatory processes in protein-specific glycosylation that we don't yet understand. For example, apart from the normal glycosylation of transferrin, glycosylation of $\mathrm{IgG}$ was abnormal in GCS1-CDG patients [59], although GCS1 is ubiquitously expressed. Cohen syndrome due to mutations in $V P S 13 B$ shows normal transferrin glycosylation as well, however, Duplomb et al. found abnormal N-glycan structures by mass spectrometry of total serum glycans [60]. They identified a decrease in sialylation and galactosylation of total serum $\mathrm{N}$ glycans, which indicates deficient Golgi N-glycosylation of specific proteins. They propose to analyze the highly glycosylated protein intercellular cell adhesion molecule 1 (ICAM1) and lysosome-associated membrane protein 2 (LAMP-2) in blood cells as a pre-screening test for Cohen syndrome.

In addition to defects in the $\mathrm{N}$-glycosylation pathway, there are many other genetic glycosylation defects (e.g., in O- and lipid-glycosylation, and synthesis of glycosaminoglycans and glycophosphatidylinositol (GPI) anchors) for which specific markers need to be developed, which would be of similar value as transferrin for defects in the N-glycosylation pathway. In conclusion, there is a clear need for additional glycoprotein biomarkers, in addition to transferrin, for efficient diagnostics of the full scope of genetic glycosylation defects.

\section{Potential glycoprotein biomarkers for diagnostic application in CDG}

An extensive number of glycoprotein biomarkers is already described in the literature for diagnosis of other types of diseases, particularly for diabetes mellitus [61], Alzheimer's disease [62], rheumatoid arthritis or other inflammatory diseases [63, 64], and cancer [65]. These proteins could be a potential glyco-marker for CDG as well, because they are readily measurable in biological matrices, and they have different type of glycosylation, or are from other origin compared to transferrin.

The analysis of glycoprotein levels of some cancer biomarkers is FDA approved as prognostic or diagnostic screening [66-68], indicated by an asterisk in the table below. The detection of most glycoproteins is still mainly based on immunoassays and electrophoresis techniques, although the application of mass spectrometric screening is starting to be explored as well. To highlight the extent of today's glycoproteomic biomarker research, Table 1 provides an overview of some key examples of candidate glycoprotein biomarkers from recent literature for the previously mentioned diseases.

As can be seen from this overview, the number of glycoproteins as diagnostic biomarker is growing for multiple diseases, see Table 1 for details and references. For some of these glycoproteins, altered glycosylation has already been investigated in more detail using mass spectrometry. In particular core or sLe ${ }^{\mathrm{X}}$ fucosylation seems to be a frequent significant change observed. It should also be noted that the glycoprotein level is often the diagnostic parameter. So ideally, both protein levels and glycosylation analysis should be included in one assay. It could be envisioned that combination of several plasma proteins with a more heterogeneous glycan composition and increased fucosylation as compared to transferrin, can be used in a panel to further increase the diagnostic efficiency for CDG-I and CDG- 
Table 1 Overview of some key examples of serum glycoprotein biomarkers from recent literature for diseases that present with altered glycoprotein levels and glycosylation abnormalities

\begin{tabular}{|c|c|c|c|c|}
\hline Glycoprotein Biomarker & Disease & $\begin{array}{l}\text { Detection on protein levels or altered } \\
\text { glycoforms }\end{array}$ & Detection technique & Reference \\
\hline \multirow[t]{4}{*}{ Transferrin $^{\mathrm{a}}$} & $-\mathrm{CDG}$ & - Glycosylation abnormalities & - IEF, QTOF & {$[50]$} \\
\hline & - Sepsis & - Decrease in sialylation & - ELLA & [93] \\
\hline & - Acute pancreatitis & - Increased fucosylation & - LC-MS/MS & [94] \\
\hline & - Ovarian cancer & - Increase of concentration & - ELISA & {$[95]^{\mathrm{a}}$} \\
\hline \multirow[t]{4}{*}{$\alpha 1$-antitrypsin } & $-\mathrm{CDG}$ & - Altered glycosylation & $-2 \mathrm{DE}$ & {$[36]$} \\
\hline & $\begin{array}{l}\text { - Chronic obstructive pulmonary } \\
\text { disease (COPD) }\end{array}$ & - Decreased concentration & - ELISA & [96] \\
\hline & - Liver cirrhosis and liver cancer & - Core and outer arm fucosylation & $\begin{array}{l}\text {-2DE, MALDI-TOF } \\
\text { - FLISA }\end{array}$ & {$[97]$} \\
\hline & - Lung cancer & - Altered glycosylation & $\begin{array}{l}\text { - Lectin microarray, } \\
\text { ELISA }\end{array}$ & [98] \\
\hline \multirow[t]{8}{*}{ Haptoglobin } & $-\mathrm{CDG}$ & - Altered glycosylation & $-2 \mathrm{DE}$ & {$[36]$} \\
\hline & - Long cancer & $-\mathrm{sLe}^{\mathrm{X}}$ increase & - HILIC, WAX-HPLC & [99] \\
\hline & - Acute phase ovarian cancer & $-\operatorname{sLe}^{\mathrm{X}}$ increase & - 2DE, NP-HPLC & {$[100]$} \\
\hline & - Stomach cancer & $-\mathrm{sLe}^{\mathrm{X}}$ increase & $\begin{array}{l}\text { - 2DE, LC-MS/MS } \\
\text { - ELISA } \\
\text { - HILIC }\end{array}$ & [101] \\
\hline & - Pancreatic cancer & - Fucosylation & $\begin{array}{l}\text { - MALDI-TOF } \\
\text { - Immunoblot }\end{array}$ & {$[102,103]$} \\
\hline & - Rheumatoid arthritis & - Reduced mannosylation & $\begin{array}{l}\text { - 2DE, MALDI-TOF } \\
\text { - WAX-HPLC } \\
\text { - ELISA }\end{array}$ & [104] \\
\hline & - Pancreatic cancer & - Changes in sialylation & - LC-MS/MS & [94] \\
\hline & - Gastric cancer & - Increase of concentration & $\begin{array}{l}\text { - ELISA } \\
\text { - MRM }\end{array}$ & [105] \\
\hline \multirow[t]{2}{*}{ Fetuin } & - Hepatocellular carcinoma (HCC) & - Fucosylation & $\begin{array}{l}\text { - LC-MS/MS } \\
\text { - FLISA }\end{array}$ & [106] \\
\hline & $\begin{array}{l}\text { - Chronic pancreatitis, pancreatic } \\
\text { cancer }\end{array}$ & $-\mathrm{sLe}^{\mathrm{X}}$ increase & $\begin{array}{l}\text { 2DE, WAX-HPLC, } \\
\text { NP-HPLC, } \\
\text { LC-MS/MS, MALDI- } \\
\text { TOF }\end{array}$ & {$[107]$} \\
\hline \multirow[t]{4}{*}{$\alpha$-1-acid glycoprotein } & $-\mathrm{CDG}$ & - Altered glycosylation & $-2 \mathrm{DE}$ & {$[36]$} \\
\hline & - Acute phase ovarian cancer & $-\mathrm{sLe}^{\mathrm{X}}$ increase & - 2DE, NP-HPLC & {$[100]$} \\
\hline & $\begin{array}{l}\text { - Chronic pancreatitis, pancreatic } \\
\text { cancer }\end{array}$ & - Increased branching and $s L e^{\mathrm{X}}$ & $\begin{array}{l}\text {-2DE, WAX-HPLC, } \\
\text { NP-HPLC, } \\
\text { LC-MS/MS, MALDI- } \\
\text { TOF }\end{array}$ & {$[107]$} \\
\hline & - Rheumatoid arthritis & - Altered mannosylation & $\begin{array}{l}\text { - 2DE, MALDI-TOF } \\
\text { - WAX-HPLC } \\
\text { - ELISA }\end{array}$ & {$[104]$} \\
\hline \multirow[t]{3}{*}{ Immunoglobulin $\mathrm{G}(\mathrm{IgG})$} & - Acute phase ovarian cancer & $-\mathrm{sLe}^{\mathrm{X}}$ increase & - 2DE, NP-HPLC & [100] \\
\hline & - Advanced ovarian cancer & $\begin{array}{l}\text { - Reduced galactosylation and sialylation } \\
\text { levels }\end{array}$ & - 2DE, NP-HPLC & {$[100]$} \\
\hline & - Stomach cancer & - Core fucosylation & $-2 \mathrm{DE}, \mathrm{LC}-\mathrm{MS} / \mathrm{MS}$ & {$[101]$} \\
\hline \multirow[t]{2}{*}{$\alpha 1$-antichymotrypsin } & - Acute phase ovarian cancer & $-\mathrm{sLe}^{\mathrm{X}}$ increase & - 2DE, NP-HPLC & {$[100]$} \\
\hline & - Alzheimer's disease & - Concentration & - Immunoassay & {$[108]$} \\
\hline$\alpha_{2}$-macroglobulin & - Sjögren's syndrome & Abnormal glycosylation & Immunoblot & [109] \\
\hline \multirow[t]{2}{*}{$\alpha$-fetoprotein ${ }^{\mathrm{a}}$} & - Liver diseases & - Core fucosylation, concentration & $-2 \mathrm{DE}$, immunoblot & [110] \\
\hline & - Liver cancer ${ }^{\mathrm{a}}$ & - Concentration & $\begin{array}{l}\text { - Anti-body (liquid } \\
\text { phase } \\
\text { binding assay) }\end{array}$ & {$[67]^{\mathrm{a}}$} \\
\hline des- $\gamma$-carboxypro-thrombin & Liver diseases, liver cancer & Core fucosylation & $-2 \mathrm{DE}$, immunoblot & {$[110]$} \\
\hline Ferritin & $\begin{array}{l}\text { Still's disease, hemophagocytic } \\
\text { syndrome }\end{array}$ & Altered glycosylation & Immunoassay & [111] \\
\hline \multirow[t]{2}{*}{ Ceruloplasmin } & $-\mathrm{CDG}$ & - Low levels, glycosylation abnormalities & $-2 \mathrm{DE}$ & {$[50]$} \\
\hline & - Hepatocellular carcinoma (HCC) & - Upregulated, core fucosylation & $\begin{array}{l}- \text { LC-MS/MS } \\
-2 \text { DE, MALDI-TOF }\end{array}$ & {$[112,113]$} \\
\hline
\end{tabular}


Table 1 (continued)

\begin{tabular}{|c|c|c|c|c|}
\hline Glycoprotein Biomarker & Disease & $\begin{array}{l}\text { Detection on protein levels or altered } \\
\text { glycoforms }\end{array}$ & Detection technique & Reference \\
\hline & - Pancreatic cancer & $-\mathrm{sLe}^{\mathrm{X}}$ increase & $\begin{array}{l}\text { - LC-MS/MS } \\
\text { - Immunoblot }\end{array}$ & [114] \\
\hline \multirow[t]{2}{*}{ Thyroglobulin $^{\mathrm{a}}$} & $-\mathrm{CDG}$ & - Low levels, glycosylation abnormalities & $-2 \mathrm{DE}$ & {$[50]$} \\
\hline & - Thyroid cancer & - Increase of concentration & - Immunoassay & {$[115],[68]^{\mathrm{a}}$} \\
\hline \multirow[t]{2}{*}{$\begin{array}{l}\text { Thyrotropin, Thyroid } \\
\text { stimulating hormone }\end{array}$} & $-\mathrm{CDG}$ & - Low levels, altered glycosylation & - IEF, serum levels & $\begin{array}{c}{[50,116} \\
117]\end{array}$ \\
\hline & - Thyroid function & - Increase of glycoprotein concentration & - Immunoassay & [118] \\
\hline Hemopexin & Hepatocellular carcinoma (HCC) & Fucosylation & $\begin{array}{l}\text { - LC-MS/MS } \\
\text { - FLISA }\end{array}$ & [106] \\
\hline \multirow[t]{3}{*}{ Clusterin } & - Stomach cancer & - Smaller N-glycans & $-2 \mathrm{DE}, \mathrm{LC}-\mathrm{MS} / \mathrm{MS}$ & [101] \\
\hline & - Gastric cancer & - Decrease of concentration & $\begin{array}{l}\text { - ELISA } \\
\text { - MRM }\end{array}$ & {$[105]$} \\
\hline & $\begin{array}{l}\text { - Clear cell renal cell } \\
\text { carcinoma }\end{array}$ & $\begin{array}{l}\text { - Decreased (core fucosylated) biantannary } \\
\text { glycans }\end{array}$ & $\begin{array}{r}\text { - SDS-PAGE, } \\
\text { LC-MS/MS } \\
\text { - Immunoblot }\end{array}$ & [119] \\
\hline $\begin{array}{l}\text { Leucine } \\
\quad \text { rich- } \alpha 2 \text {-glycoprotein }\end{array}$ & Stomach cancer & Upregulation, altered glycosylation & 2DE, LC-MS/MS & {$[101,120]$} \\
\hline$\alpha$-dystroglycan & Walker-Warburg syndrome & Hypoglycosylation & Immunoassay & {$[121]$} \\
\hline \multirow[t]{2}{*}{ Kininogen } & - Colorectal cancer (CRC) & $\begin{array}{l}\text { - Elevated sialylation and } \\
\text { fucosylation }\end{array}$ & $\begin{array}{l}\text { - LC-MS/MS } \\
\text { - Lectin microarray }\end{array}$ & [122] \\
\hline & - Colorectal cancer (CRC) & - Increase of concentration & $\begin{array}{l}\text { - MALDI-TOF } \\
\text { - ELISA } \\
\text { - Immunostaining }\end{array}$ & [123] \\
\hline Kallistatin & Liver cirrhosis & Increase of concentration & ELISA & {$[124]$} \\
\hline \multirow[t]{2}{*}{ Afamin } & - Metabolic syndrome & - Increase of concentration & - ELISA & [125] \\
\hline & - Gastric cancer & - Decrease of concentration & $\begin{array}{l}\text { - ELISA } \\
\text { - MRM }\end{array}$ & {$[105]$} \\
\hline Prostate Specific Antigen (PSA) ${ }^{\mathrm{a}}$ & Prostate cancer & Increase of concentration & Immunoassay & {$[126],[68]^{\mathrm{a}}$} \\
\hline $\begin{array}{l}\text { Human chorionic } \\
\text { gonadotrophin (hCG) }\end{array}$ & $\begin{array}{l}\text { - Ovarian tumors } \\
\text { - Testicular tumors }\end{array}$ & Increase of concentration & Immunoassay & {$[68],[66]^{\mathrm{a}}$} \\
\hline Apolipoprotein $(\mathrm{A}-1)^{\mathrm{a}}$ & Ovarian cancer & Decrease of concentration & ELISA & {$[95]^{\mathrm{a}}$} \\
\hline Transthyretin, prealbumin $^{\mathrm{a}}$ & Ovarian cancer & Decrease of concentration & ELISA & {$[95]^{\mathrm{a}}$} \\
\hline$\beta 2$-microglobulin ${ }^{\mathrm{a}}$ & Ovarian cancer & Increase of concentration & ELISA & {$[95]^{\mathrm{a}}$} \\
\hline $\begin{array}{l}\text { Cancer antigen } 125 \\
\text { (CA125) or MUC16 }\end{array}$ & Ovarian cancer & Increase of concentration & ELISA & {$[67,95]^{\mathrm{a}}$} \\
\hline $\begin{array}{l}\text { Carbohydrate antigen 19-9 } \\
\quad(\text { CA19-9) })^{\mathrm{a}}\end{array}$ & $\begin{array}{l}\text { - Pancreatic cancer Ovarian } \\
\text { cancer }\end{array}$ & $\operatorname{sLe}^{\mathrm{a}}$ on mucin glycoproteins & ELISA & {$[64,68]^{\mathrm{a}}$} \\
\hline $\begin{array}{l}\text { Cancer antigen 15-3 } \\
\quad(\text { CA15-3 })^{\mathrm{a}}\end{array}$ & Breast cancer & Sialylated O-linked oligosaccharide on MUC1 & ELISA & {$[67,68]^{\mathrm{a}}$} \\
\hline CA27-29 (MUC1) & Breast cancer & Protein concentration & ELISA & {$[67,68]^{\mathrm{a}}$} \\
\hline
\end{tabular}

2DE 2D-electrophoresis; ELLA enzyme-linked lectin assay; FLISA Lectin-Fluorophore-linked Immunosorbent Assay; HILIC Hydrophilic Interaction Liquid Chromatography; $s L e^{a}$ Sialyl Lewis A structures; $s L e^{X}$ Sialyl Lewis X structures; WAX-HPLC weak anion exchange high performance liquid chromatography

${ }^{a}$ FDA approved

II. Apart from selections based on biological aspects as discussed in section 4.1, an additional challenge is the mass spectrometric compatibility and the different approaches for analysis, which will be discussed in the next paragraph.

\section{Mass spectrometry in glycoprotein analysis}

A growing number of protein biomarkers are analyzed in the clinics by mass spectrometry. Mass spectrometry is ideally suited for the clinical laboratory, because the technique is sensitive, compatible with biological matrices, suitable for highthroughput analyses and it provides detailed structural information. The technique has proven itself for CDG diagnostics through the routine analysis of serum transferrin, which will pave the way in the search for additional glycoprotein biomarkers. In Fig. 3, an overview is depicted of the different levels of glycosylation analysis by mass spectrometry, better known as Glycomics. Intact glycoprotein analysis provides quantitative glycan structural information of the intact glycoprotein. 
Quantification is possible with the assumption that ionization of the molecules dominated by the amino acid backbone. Loss of complete glycans can therefore accurately be detected. Intact protein analysis is limited by size and hydrophobicity of the protein, and limited by the number of glycosylation sites for correct interpretation of the spectra. Glycopeptide analysis provides detailed site-specific information on glycan forms, and enzymatic digestions increase the chance to measure large or hydrophobic proteins of interest. However, the ionization efficiency is influenced by the type of glycan, which hampers any quantitative comparison between different glycoforms. Analysis of free glycans allows sensitive detection of very low abundant glycan structures, however information on the corresponding protein/peptide attachment site is lost. Therefore, each detection technique has its own strengths and weaknesses depending on the intended goal of the analysis. Below, we discuss the use of mass spectrometry in biomarker discovery and for its potential use as a diagnostic test.

\section{Glycoprotein biomarker discovery}

The most widely used methods for biomarker discovery within the field of glycomics includes free N-glycan profiling of a biological fluid, such as serum, plasma or cerebrospinal fluid. Many groups have published on the discovery of altered glycosylation in a wide variety of diseases, and convincingly showed that glycans have potential as biomarkers, being highly sensitive to pathological changes [69-73]. Thus far, only a very limited number of potential biomarkers based on free glycan profiling is further developed and used in a real clinical diagnostic test, one example being the GlycoCirrhoTest [74] for distinguishing cirrhotic from non-cirrhotic chronic liver disease patients.

Two major limitations of total serum N-glycan analysis create the basis for improvement: First, the information to which proteins glycans were attached, is lost in total serum $\mathrm{N}$-glycan analysis. Secondly, alterations in glycosylation are biased by fluctuations in the dynamic N-glycoproteome, which are dependent on environmental factors such as an immune response [75-78]. Ideally, profiling methods need to be used that take into account the protein to which the altered glycans are attached, such as profiling of intact glycopeptides from complex biological samples. Recent technical developments and improved databases seem to make this challenge feasible. A combination of collision induced dissociation (CID) and electron-transfer dissociation (ETD) fragmentation techniques is preferred to characterize glycopeptides [79, 80]. While CID provides information related to the composition and structure of glycan moieties attached to a peptide backbone, ETD fragments mainly the peptide backbone and leaves the glycan intact, permitting de novo sequencing of the peptide moiety $[81,82]$. Due to the relative low abundance and low ionization efficiency of glycopeptides, glycoproteins need to be enriched, digested and chromatographically separated for this type of analyses. Since the glycan moiety makes the glycopeptide generally more polar, HILIC is a commonly used enrichment strategy for glycopeptides [83]. Other usual approaches are immune-affinity (reactive beads) [84, 85] or lectin-affinity purifications [86, 87]. Furthermore, commercial kits are available to deplete serum samples from the most abundant serum proteins, although that might cause potential biomarkers (see Table 1) to be lost. Combining these techniques enables unambiguous in-depth identification of both the peptide and the glycan. However, the data analysis software is not yet sophisticated enough to enable automated sequencing of peptides and combining search results from both fragmentation techniques for identification. Therefore, intact glycopeptide analysis from complex biological samples is still far from being a routine diagnostic analysis. Within a research environment, glycopeptide profiling is highly promising for the identification of new glycoprotein biomarkers.

One first example of glycopeptide analysis using the combination of CID and ETD fragmentation, is a very recent study of Medzihradszky et al. on tissue-specific glycosylation [58, 88]. They compared the glycosylation patterns of mouse liver with brain tissue and not only found that these patterns differ by the cellular location of the glycoprotein (e.g., ER, lysosomal or transmembrane), but also showed tissue-specific differences for the same protein.

\section{Glycoprotein biomarker application in clinical diagnostics}

Diagnostic assays are required to be fast, robust and suitable for high-throughput measurements, while in addition the interpretation in a clinical setting should be straightforward. Free Nglycan analysis meets the technical requirements, however, diagnostic interpretation is highly complicated due to the many causes that influence N-glycan profiles. For some well-defined CDG subtypes with a clear genetic defect, such as B4GALT1CDG and MGAT2-CDG, interpretation is clear. However, abnormalities in free $\mathrm{N}$-glycan profiles for other defects are more subtle or overlapping with multiple defects. Examples include PGM1-CDG, where the lack of complete glycans is not found in total serum N-glycan profiles and only minimal loss of galactose is not sufficiently specific to reach a diagnosis.

Diagnostic application of glycopeptides is of particular interest, because multiple identified biomarkers could subsequently be used for diagnostic high-throughput screening by means of multiple/serial reaction monitoring (MRM/SRM), similar as is increasingly used for the detection of protein biomarkers in clinical diagnostics. In this sensitive targeted analysis, specific (transitions of) predefined precursor ions are sequentially selected for MS/MS detection in a quantitative and reproducible manner [89]. For instance, Hong et al. developed an MRM analysis to analyze the $\operatorname{IgG}$ free glycans in whole serum. By normalizing protein glycosylation to 
Fig. 3 Schematic representation of the different types of glycoprotein analysis using mass spectrometry

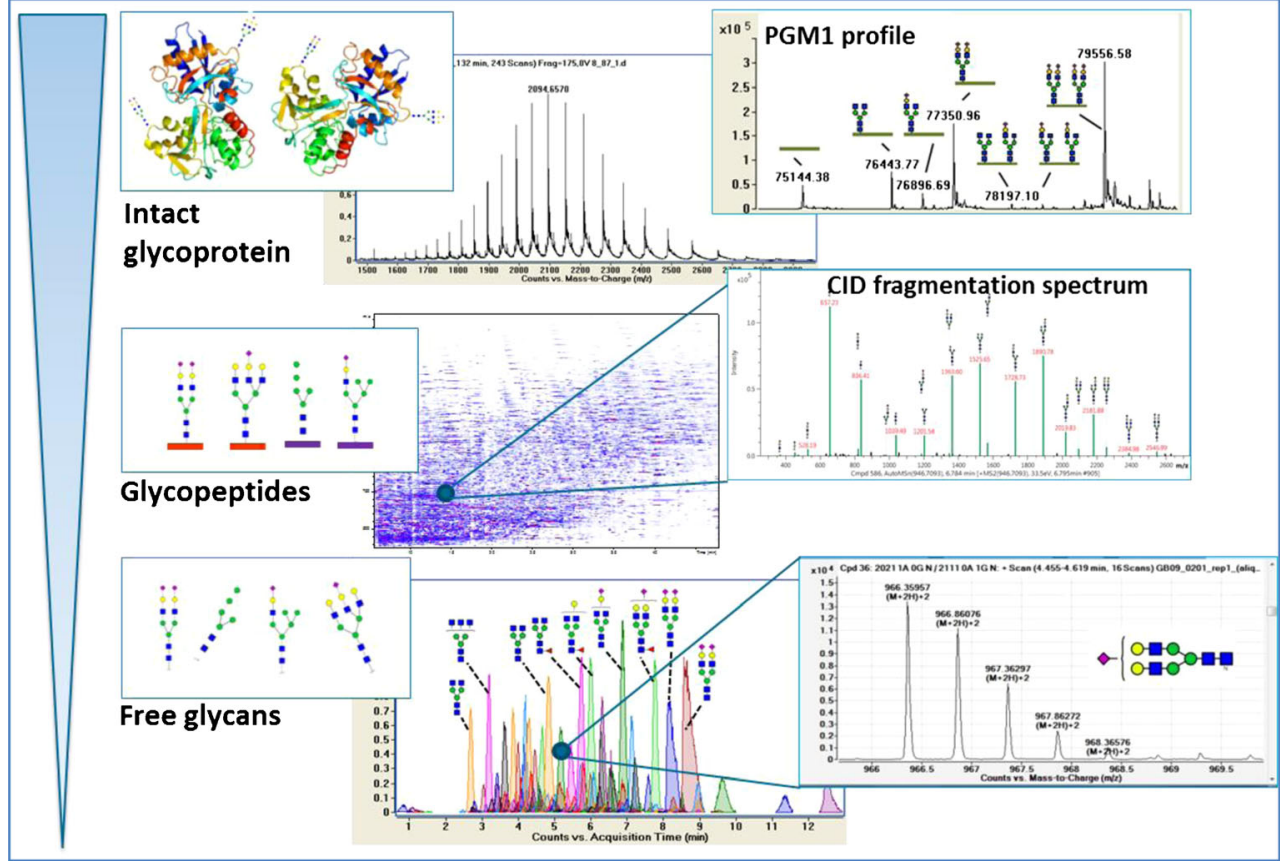

absolute protein concentrations they were able to examine quantitative changes in glycosylation at site-specific level [90], which is crucial to distinguish between altered glycosylation and change in protein levels. Hulsmeier et al. published a MRM method to quantify the N-glycosylation site occupancy for transferrin and $\alpha_{1}$-antitrypsin, and found out that the site occupancy correlated well with the severity of the disease [91]. Moreover, they observed preferences for specific occupation sites. The method could in principle easily be extended to multiple glycoproteins.

Very recently, Sun et al. proposed a new method to measure absolute protein glycosylation stoichiometry in complex biological samples [92]. They use the relative ratios between the N-glycosylated peptide, the peptide without the glycans and the complete glycoprotein from the same type of biological sample to profile the glycosylation occupancy and glycoform stoichiometry and determined 117 absolute Nglycosylation occupancies in OVCAR-3 cells. Application to CDG has not been tested yet, but might be promising in biomarker discovery.

A specific set of intact glycoproteins would have several advantages over glycopeptide mixtures, mainly improving on the relative quantification. One needs to consider that transferrin is a relative simple glycoprotein to analyze as it has only two glycosylation sites, whereas other proteins might go up to multiple glycosylation sites and increased glycan heterogeneity. Each additional glycosylation site will complicate annotation [83]. In addition, an antibody would be required to affinity-purify the protein from the biological complex sample. The antibody would need to have its epitope outside of any glycosylation motif, to ensure glycosylation-independent purification of all glycoforms.

Overall, each method has its strengths and weaknesses. Targeted, MRM based mass spectrometry of glycopeptides is fast, robust and sensitive, allowing complex mixtures to be analyzed. With intact glycoprotein analysis, a limited number of proteins can be analyzed. However, all glycoforms of one protein are measured simultaneously in the mass spectrometer, which allows relative quantification of glycoforms and easy comparison of both CDG type-I and CDG type-II defects in one spectrum.

\section{Outlook}

The ultimate goal in clinical diagnostics of CDG would be to cover the complete field of glycosylation disorders in a single or only few assays. This would not only benefit diagnostics of monogenic, inherited disorders of glycosylation, but also the more common, complex genetic disorders like cancer, Alzheimer or inflammatory diseases. Several diseases show abnormal glycosylation, and an increasing number of glycosylation disorders is identified by next generation sequencing techniques. More and more defects within the newly discovered disorders are found outside the pathway of protein $\mathrm{N}$ glycosylation, for example defects in energy metabolism, or GPI-defects. To include these defects, the repertoire of glycoprotein biomarkers should be expanded, by analyzing a welldefined set of multiple, intact biomarker glycoproteins. 
Table 1 provides an overview of glycoprotein biomarkers, which are worth considering for clinical diagnostics of CDG. It lists candidates which are already applied in clinical laboratories for other types of diseases, so addition of these proteins should be feasible. Our preference is to include several proteins in one assay, either as glycopeptides or as intact proteins. The intact transferrin spectra already show the potential to develop a unique classification system for CDG. The spectra provide such a characteristic profile that clinical diagnostics is possible at a glance $[20,43]$.

When glycoproteins are digested, housekeeping proteins or non-glycosylated peptides of a targeted glycoprotein are necessary for normalization and quantification purposes. In addition, improved ionization and enhanced separation for low abundant glycopeptides might be required. When followed by high-resolution detection and adequate databases for automated searches, automated MRM analyses can be used as a fast diagnostic test. Until then, we propose that intact glycoprotein profiling of well-defined protein mixtures will have the best potential for CDG diagnostics and therapy monitoring in the near future.

In conclusion, simultaneous analysis of multiple glycoproteins would highly increase our knowledge of the glycosylation machinery in different types of cells, and improve our diagnostic power to sensitively and specifically monitor disease in CDG patients. A highly detailed glycosylation readout of individual proteins would work in synergy with Next Generation Sequencing techniques in the identification of new inherited disorders. Also, the diagnostics of more common disorders shall benefit from the lessons that will be learned from the analysis of complex glycoprotein mixtures.

\begin{abstract}
Acknowledgments This work was supported by the Dutch Organisation for Scientific Research, NWO (Medium Investment Grant 40-0050698-9001 and VIDI Grant 91713359 to DL).
\end{abstract}

Open Access This article is distributed under the terms of the Creative Commons Attribution 4.0 International License (http:// creativecommons.org/licenses/by/4.0/), which permits unrestricted use, distribution, and reproduction in any medium, provided you give appropriate credit to the original author(s) and the source, provide a link to the Creative Commons license, and indicate if changes were made.

\section{References}

1. Mechref, Y., et al.: Identifying cancer biomarkers by mass spectrometry-based glycomics. Electrophoresis 33(12), 17551767 (2012)

2. Miwa, H.E., et al.: The bisecting GlcNAc in cell growth control and tumor progression. Glycoconj. J. 29(8-9), 609-618 (2012)

3. Büll, C., et al.: Targeting aberrant sialylation in cancer cells using a fluorinated sialic acid analog impairs adhesion, migration, and in vivo tumor growth. Mol. Cancer Ther. 12(10), 1935-1946 (2013)
4. Gornik, O., Lauc, G.: Glycosylation of serum proteins in inflammatory diseases. Dis. Markers 25(4-5), 267-278 (2008)

5. Schedin-Weiss, S., Winblad, B., Tjernberg, L.O.: The role of protein glycosylation in Alzheimer disease. FEBS J. 281(1), 46-62 (2014)

6. Bunn, H.F., Gabbay, K.H., Gallop, P.M.: The glycosylation of hemoglobin: relevance to diabetes mellitus. Science 200(4337), 21-27 (1978)

7. Thanabalasingham, G., et al.: Mutations in HNF1A result in marked alterations of plasma glycan profile. Diabetes 62(4), 1329-1337 (2013)

8. Freeze, H.H., et al.: Solving glycosylation disorders: fundamental approaches reveal complicated pathways. Am. J. Hum. Genet. 94(2), 161-175 (2014)

9. Jaeken, J.: CDG nomenclature: time for a change! Biochimica et Biophysica Acta (BBA)-Molecular Basis of Disease 1792(9), 825-826 (2009)

10. Jaeken, J., van den Heuvel L.: Congenital disorders of glycosylation, in physician's guide to the diagnosis, treatment, and followup of inherited metabolic diseases. Springer. p. 483-512 (2014)

11. Hennet, T.: Diseases of glycosylation beyond classical congenital disorders of glycosylation. Biochimica et Biophysica Acta (BBA)General Subjects 1820(9), 1306-1317 (2012)

12. Scott, K., et al.: Congenital disorders of glycosylation: new defects and still counting. J. Inherit. Metab. Dis. 37(4), 609-617 (2014)

13. Grünewald, S., Matthijs, G., Jaeken, J.: Congenital disorders of glycosylation: a review. Pediatr. Res. 52(5), 618-624 (2002)

14. Wolfe, L.A., Krasnewich, D.: Congenital disorders of glycosylation and intellectual disability. Developmental disabilities research reviews 17(3), 211-225 (2013)

15. Wada, Y.: Mass spectrometry for congenital disorders of glycosylation, CDG. J. Chromatogr. B 838(1), 3-8 (2006)

16. Morelle, W., Michalski, J.-C.: Analysis of protein glycosylation by mass spectrometry. Nat. Protoc. 2(7), 1585-1602 (2007)

17. Guillard, M., et al.: Automated measurement of permethylated serum N-glycans by MALDI-linear ion trap mass spectrometry. Carbohydr. Res. 344(12), 1550-1557 (2009)

18. Sturiale, L., Barone, R., Garozzo, D.: The impact of mass spectrometry in the diagnosis of congenital disorders of glycosylation. J. Inherit. Metab. Dis. 34(4), 891-899 (2011)

19. Lacey, J.M., et al.: Rapid determination of transferrin isoforms by immunoaffinity liquid chromatography and electrospray mass spectrometry. Clin. Chem. 47(3), 513-518 (2001)

20. Tegtmeyer, L.C., et al.: Multiple phenotypes in phosphoglucomutase 1 deficiency. N. Engl. J. Med. 370(6), 533-542 (2014)

21. Matthijs, G., et al.: Approaches to homozygosity mapping and exome sequencing for the identification of novel types of CDG. Glycoconj. J. 30(1), 67-76 (2013)

22. Jaeken, J.: Congenital disorders of glycosylation. Ann. N. Y. Acad. Sci. 1214(1), 190-198 (2010)

23. Jaeken, J., et al.: Sialic acid-deficient serum and cerebrospinal fluid transferrin in a newly recognized genetic syndrome. Clin. Chim. Acta 144(2), 245-247 (1984)

24. Helander, A., Husa, A., Jeppsson, J.-O.: Improved HPLC method for carbohydrate-deficient transferrin in serum. Clin. Chem. 49(11), 1881-1890 (2003)

25. Carchon, H.A., et al.: Diagnosis of congenital disorders of glycosylation by capillary zone electrophoresis of serum transferrin. Clin. Chem. 50(1), 101-111 (2004)

26. Sanz-Nebot, V., et al.: Characterization of transferrin glycoforms in human serum by CE-UV and CE-ESI-MS. Electrophoresis 28(12), 1949-1957 (2007)

27. Lefeber, D.J., Morava, E., Jaeken, J.: How to find and diagnose a CDG due to defective N-glycosylation. J. Inherit. Metab. Dis. 34(4), 849-852 (2011) 
28. Albahri, Z., et al.: Genetic variants of transferrin in the diagnosis of protein hypoglycosylation. J. Inherit. Metab. Dis. 28(6), 1184 $1188(2005)$

29. Zühlsdorf, A., et al.: Transferrin variants: Pitfalls in the diagnostics of congenital disorders of glycosylation. Clin. Biochem. 48(1), 11-13 (2015)

30. Kühnl, P., Spielmann, W.: Transferrin: evidence for two common subtypes of the TfC allele. Hum. Genet. 43(1), 91-95 (1978)

31. van Scherpenzeel, M., et al.: High-resolution Qtof-MS glycoprofiling of intact transferrin for diagnosis and subtype identification in the congenital disorders of glycosylation. Translational Res, (2015)

32. Jaeken, J.: Congenital disorders of glycosylation (CDG): it's (nearly) all in it! J. Inherit. Metab. Dis. 34(4), 853-858 (2011)

33. Gao, N., Lehrman, M.A.: Analyses of dolichol pyrophosphatelinked oligosaccharides in cell cultures and tissues by fluorophoreassisted carbohydrate electrophoresis. Glycobiology 12(5), 353$360(2002)$

34. Timal, S., et al.: Gene identification in the congenital disorders of glycosylation type I by whole-exome sequencing. Hum. Mol. Genet. 21(19), 4151-4161 (2012)

35. Wopereis, S., et al.: Transferrin and apolipoprotein C-III isofocusing are complementary in the diagnosis of $\mathrm{N}$-and $\mathrm{O}$-glycan biosynthesis defects. Clin. Chem. 53(2), 180-187 (2007)

36. Bruneel, A., et al.: Two-dimensional gel electrophoresis of apolipoprotein $\mathrm{C}$-III and other serum glycoproteins for the combined screening of human congenital disorders of $\mathrm{O}$-and $\mathrm{N}$-glycosylation. PROTEOMICS-Clinical Applications 1(3), 321-324 (2007)

37. Wada, Y., Tajiri, M., Yoshida, S.: Hydrophilic affinity isolation and MALDI multiple-stage tandem mass spectrometry of glycopeptides for glycoproteomics. Anal. Chem. 76(22), 6560-6565 (2004)

38. Guillard, M., et al.: Plasma N-glycan profiling by mass spectrometry for congenital disorders of glycosylation type II. Clin. Chem. 57(4), 593-602 (2011)

39. Xia, B., et al.: Serum N-glycan and O-glycan analysis by mass spectrometry for diagnosis of congenital disorders of glycosylation. Anal. Biochem. 442(2), 178-185 (2013)

40. Wada, Y., Kadoya, M., Okamoto, N.: Mass spectrometry of apolipoprotein C-III, a simple analytical method for mucin-type Oglycosylation and its application to an autosomal recessive cutis laxa type-2 (ARCL2) patient. Glycobiology 22(8), 1140-1144 (2012)

41. Faid, V., et al.: A rapid mass spectrometric strategy for the characterization of $\mathrm{N}$-and $\mathrm{O}$-glycan chains in the diagnosis of defects in glycan biosynthesis. Proteomics 7(11), 1800-1813 (2007)

42. Yen-Nicolaÿ, S., et al.: MALDI-TOF MS applied to apoC-III glycoforms of patients with congenital disorders affecting O-glycosylation. Comparison with two-dimensional electrophoresis. PROTEOMICS-Clinical Applications, (2015)

43. Van Scherpenzeel, M., et al.: Diagnostic serum glycosylation profile in patients with intellectual disability as a result of MAN1B1 deficiency. Brain 137(4), 1030-1038 (2014)

44. Freeze, H.H.: Towards a therapy for phosphomannomutase 2 deficiency, the defect in CDG-Ia patients. Biochimica et Biophysica Acta (BBA)-Molecular Basis of Disease 1792(9), 835-840 (2009)

45. De Lonlay, P., Seta, N.: The clinical spectrum of phosphomannose isomerase deficiency, with an evaluation of mannose treatment for CDG-Ib. Biochimica et Biophysica Acta (BBA)-Molecular Basis of Disease 1792(9), 841-843 (2009)

46. Marquardt, T., et al.: Correction of leukocyte adhesion deficiency type II with oral fucose. Blood 94(12), 3976-3985 (1999)

47. Almeida, A., Layton, M., Karadimitris, A.: Inherited glycosylphosphatidyl inositol deficiency: a treatable CDG. Biochimica et Biophysica Acta (BBA)-Molecular Basis of Disease 1792(9), 874-880 (2009)
48. Almeida, A.M., et al.: Targeted therapy for inherited GPI deficiency. N. Engl. J. Med. 356(16), 1641-1647 (2007)

49. Freeze, H.H., Aebi, M.: Molecular basis of carbohydrate-deficient glycoprotein syndromes type I with normal phosphomannomutase activity. Biochimica et Biophysica Acta (BBA)-Molecular Basis of Disease 1455(2), 167-178 (1999)

50. Janssen, M.C., et al.: Successful liver transplantation and longterm follow-up in a patient with MPI-CDG. Pediatrics 134(1), e279-e283 (2014)

51. Quick, C.B., Fisher, R.A., Harris, H.: A kinetic study of the isozymes determined by the three human phosphoglucomutase loci PGM1, PGM2 and PGM3. Eur. J. Biochem. 42(2), 511-517 (1974)

52. Etzioni, A., et al.: Leukocyte adhesion deficiency (LAD) type II/ carbohydrate deficient glycoprotein (CDG) IIc founder effect and genotype/phenotype correlation. Am. J. Med. Genet. 110(2), 131135 (2002)

53. Marquardt, T., et al.: Leukocyte adhesion deficiency II syndrome, a generalized defect in fucose metabolism. J. Pediatr. 134(6), 681688 (1999)

54. Cagdas, D., et al.: A novel mutation in leukocyte adhesion deficiency type II/CDGIIc. J. Clin. Immunol. 34(8), 1009-1014 (2014)

55. Maeda, Y., et al.: PIG-M transfers the first mannose to glycosylphosphatidylinositol on the lumenal side of the ER. The EMBO journal 20(1-2), 250-261 (2001)

56. Varki, A., et al.: Essentials of glycobiology. 2nd ed. Chapter 13: Cold Spring (2009)

57. Zielinska, D.F., et al.: Precision mapping of an in vivo Nglycoproteome reveals rigid topological and sequence constraints. Cell 141(5), 897-907 (2010)

58. Medzihradszky, K.F., Kaasik, K., Chalkley, R.J.: Tissue-specific glycosylation at the glycopeptide level. Mol. Cell. Proteomics M115, 050393 (2015)

59. Sadat, M.A., et al.: Glycosylation, hypogammaglobulinemia, and resistance to viral infections. N. Engl. J. Med. 370(17), 1615-1625 (2014)

60. Duplomb, L., et al.: Cohen syndrome is associated with major glycosylation defects. Human molecular genetics, p. ddt630 (2013)

61. Testa, R., et al.: N-Glycomic changes in serum proteins in type 2 diabetes mellitus correlate with complications and with metabolic syndrome parameters. PLoS One 10(3), e0119983 (2015)

62. Kitazume, S.: Glycosylation of amyloid $\beta$ precursor protein, pp. 1283-1288. Biology and Medicine, Glycoscience (2015)

63. Albrecht, S., et al.: Glycosylation as a marker for inflammatory arthritis. Cancer Biomark 14, 17-28 (2014)

64. Angata, T., et al.: Integrated approach toward the discovery of glyco-biomarkers of inflammation-related diseases. Ann. N. Y. Acad. Sci. 1253(1), 159-169 (2012)

65. Adamczyk, B., Tharmalingam, T., Rudd, P.M.: Glycans as cancer biomarkers. Biochimica et Biophysica Acta (BBA)-General Subjects 1820(9), 1347-1353 (2012)

66. Ludwig, J.A., Weinstein, J.N.: Biomarkers in cancer staging, prognosis and treatment selection. Nat. Rev. Cancer 5(11), 845-856 (2005)

67. Shinohara, Y., Furukawa, J.-I., Miura Y.: Glycome as biomarkers. General Methods Biomarker Res their Appl, p. 111-140 (2015)

68. Kirwan, A., et al.: Glycosylation-based serum biomarkers for cancer diagnostics and prognostics. BioMed Res Int, 2015. (2015)

69. Chu, C.S., et al.: Profile of native N-linked glycan structures from human serum using high performance liquid chromatography on a microfluidic chip and time-of-flight mass spectrometry. Proteomics 9(7), 1939 (2009) 
70. Song, T., Aldredge, D., Lebrilla, C.B.: A method for in-depth structural annotation of human serum glycans that yields biological variations. Anal. Chem. 87(15), 7754-7762 (2015)

71. Leymarie, N., Zaia, J.: Effective use of mass spectrometry for glycan and glycopeptide structural analysis. Anal. Chem. 84(7), 3040-3048 (2012)

72. Wuhrer, M.: Glycomics using mass spectrometry. Glycoconj. J. 30(1), 11-22 (2013)

73. Stoeckmann, H., et al.: Ultra-high throughput, ultrafiltration-based $\mathrm{N}$-glycomics platform for ultra-performance liquid chromatography (ULTRA3). Analytical Chem, (2015)

74. Callewaert, N., et al.: Noninvasive diagnosis of liver cirrhosis using DNA sequencer-based total serum protein glycomics. Nat. Med. 10(4), 429-434 (2004)

75. Ota, H., et al.: Helicobacter pylori infection produces reversible glycosylation changes to gastric mucins. Virchows Arch. 433(5), 419-426 (1998)

76. Tangvoranuntakul, P., et al.: Human uptake and incorporation of an immunogenic nonhuman dietary sialic acid. Proc. Natl. Acad. Sci. 100(21), 12045-12050 (2003)

77. Knezevic, A., et al.: Variability, heritability and environmental determinants of human plasma N-glycome. J. Proteome Res. 8(2), 694-701 (2008)

78. Butler, M., et al.: Detailed glycan analysis of serum glycoproteins of patients with congenital disorders of glycosylation indicates the specific defective glycan processing step and provides an insight into pathogenesis. Glycobiology 13(9), 601-622 (2003)

79. Alley, W.R., Mechref, Y., Novotny, M.V.: Characterization of glycopeptides by combining collision-induced dissociation and electron-transfer dissociation mass spectrometry data. Rapid Commun. Mass Spectrom. 23(1), 161-170 (2009)

80. Mechref, Y.: Use of CID/ETD mass spectrometry to analyze glycopeptides. Current Protocols Protein Sci: p. 12.11. 1-12.11. 11 (2012)

81. Wuhrer, M., et al.: Glycoproteomics based on tandem mass spectrometry of glycopeptides. J. Chromatogr. B 849(1), 115-128 (2007)

82. Ma, B., Johnson R.: De novo sequencing and homology searching. Mol. Cell. Proteomics. 11(2): p. O111. 014902 (2012)

83. Khatri, K., et al.: Confident assignment of site-specific glycosylation in complex glycoproteins in a single step. J. Proteome Res. 13(10), 4347-4355 (2014)

84. Whiteaker, J.R., et al.: Sequential multiplexed analyte quantification using peptide immunoaffinity enrichment coupled to mass spectrometry. Molecular \& Cellular Proteomics. 11(6): p. M111. 015347 (2012)

85. Ongay, S., et al.: Glycopeptide enrichment and separation for protein glycosylation analysis. J. Sep. Sci. 35(18), 2341-2372 (2012)

86. Yang, Z., Hancock, W.S.: Approach to the comprehensive analysis of glycoproteins isolated from human serum using a multi-lectin affinity column. J. Chromatogr. A 1053(1), 79-88 (2004)

87. Wang, Y., Wu, S.-1., Hancock, W.S.: Approaches to the study of $\mathrm{N}$-linked glycoproteins in human plasma using lectin affinity chromatography and nano-HPLC coupled to electrospray linear ion trap-Fourier transform mass spectrometry. Glycobiology 16(6), 514-523 (2006)

88. Trinidad, J.C., et al.: $\mathrm{N}$-and O-glycosylation in the murine synaptosome. Mol. Cell. Proteomics 12(12), 3474-3488 (2013)

89. Picotti, P., Aebersold, R.: Selected reaction monitoring-based proteomics: workflows, potential, pitfalls and future directions. Nat. Methods 9(6), 555-566 (2012)

90. Hong, Q., et al.: Absolute quantitation of immunoglobulin $\mathrm{G}$ and its glycoforms using multiple reaction monitoring. Anal. Chem. 85(18), 8585-8593 (2013)

91. Hülsmeier, A.J., Paesold-Burda, P., Hennet, T.: N-glycosylation site occupancy in serum glycoproteins using multiple reaction monitoring liquid chromatography-mass spectrometry. Mol. Cell. Proteomics 6(12), 2132-2138 (2007)

92. Sun, S., Zhang H.: Large-scale measurement of absolute protein glycosylation stoichiometry. Analytical Chem, (2015)

93. Gornik, O., et al.: Change of transferrin sialylation differs between mild sepsis and severe sepsis and septic shock. Intern. Med. 50(8), 861-869 (2011)

94. Kontro, H., et al.: Comparison of sialylated N-glycopeptide levels in serum of pancreatic cancer patients, acute pancreatitis patients, and healthy controls. Proteomics 14(15), 1713-1723 (2014)

95. Abraham, J.: OVA1 test for preoperative assessment of ovarian cancer. Commun. Oncol. 7(6), 249-250 (2010)

96. Stockley, R.A., Turner, A.M.: $\alpha$-1-Antitrypsin deficiency: clinical variability, assessment, and treatment. Trends Mol. Med. 20(2), 105-115 (2014)

97. Comunale, M.A., et al.: Linkage specific fucosylation of alpha-1antitrypsin in liver cirrhosis and cancer patients: implications for a biomarker of hepatocellular carcinoma. (2010)

98. Liang, Y., et al.: Differentially expressed glycosylated patterns of alpha-1-antitrypsin as serum biomarkers for the diagnosis of lung cancer. Glycobiology: p. cwu115 (2014)

99. Arnold, J.N., et al.: Novel glycan biomarkers for the detection of lung cancer. J. Proteome Res. 10(4), 1755-1764 (2011)

100. Saldova, R., et al.: Ovarian cancer is associated with changes in glycosylation in both acute-phase proteins and IgG. Glycobiology 17(12), 1344-1356 (2007)

101. Bones, J., et al.: Glycomic and glycoproteomic analysis of serum from patients with stomach cancer reveals potential markers arising from host defense response mechanisms. J. Proteome Res. 10(3), 1246-1265 (2010)

102. Okuyama, N., et al.: Fucosylated haptoglobin is a novel marker for pancreatic cancer: a detailed analysis of the oligosaccharide structure and a possible mechanism for fucosylation. Int. J. Cancer 118(11), 2803-2808 (2006)

103. Miyoshi, E., Nakano, M.: Fucosylated haptoglobin is a novel marker for pancreatic cancer: detailed analyses of oligosaccharide structures. Proteomics 8(16), 3257-3262 (2008)

104. Saroha, A., et al.: Altered glycosylation and expression of plasma alpha-1-acid glycoprotein and haptoglobin in rheumatoid arthritis. J. Chromatogr. B 879(20), 1839-1843 (2011)

105. Humphries, J.M., et al.: Identification and validation of novel candidate protein biomarkers for the detection of human gastric cancer. Biochimica et Biophysica Acta (BBA)-Proteins and Proteomics 1844(5), 1051-1058 (2014)

106. Comunale, M.A., et al.: Identification and development of fucosylated glycoproteins as biomarkers of primary hepatocellular carcinoma. J. Proteome Res. 8(2), 595-602 (2008)

107. Sarrats, A., et al.: Glycosylation of liver acute-phase proteins in pancreatic cancer and chronic pancreatitis. PROTEOMICSClinical Applications 4(4), 432-448 (2010)

108. Lieberman, J., et al.: Serum $\alpha 1$-antichymotrypsin level as a marker for Alzheimer-type dementia. Neurobiol. Aging 16(5), 747-753 (1995)

109. Saso, L., et al.: Abnormal glycosylation of $\alpha 2$-macroglobulin, a non-acute-phase protein, in patients with autoimmune diseases. Inflammation 17(4), 465-479 (1993)

110. Mehta, A., Block, T.M.: Fucosylated glycoproteins as markers of liver disease. Dis. Markers 25(4-5), 259-265 (2008)

111. Fardet, L., et al.: Low glycosylated ferritin, a good marker for the diagnosis of hemophagocytic syndrome. Arthritis \& Rheumatism 58(5), 1521-1527 (2008)

112. Yin, H., et al.: Mass-selected site-specific core-fucosylation of ceruloplasmin in alcohol-related hepatocellular carcinoma. J. Proteome Res. 13(6), 2887-2896 (2014) 
113. Comunale, M.A., et al.: Proteomic analysis of serum associated fucosylated glycoproteins in the development of primary hepatocellular carcinoma. J. Proteome Res. 5(2), 308-315 (2006)

114. Balmaña, M., et al.: Identification of potential pancreatic cancer serum markers: increased sialyl-Lewis X on ceruloplasmin. Clin. Chim. Acta 442, 56-62 (2015)

115. Baudin, E., et al.: Positive predictive value of serum thyroglobulin levels, measured during the first year of follow-up after thyroid hormone withdrawal, in thyroid cancer patients. The Journal of Clinical Endocrinology \& Metabolism 88(3), 1107-1111 (2003)

116. Mohamed, M., et al.: Thyroid function in PMM2-CDG: diagnostic approach and proposed management. Mol. Genet. Metab. 105(4), 681-683 (2012)

117. Macchia, P.E., et al.: Thyroid function tests and characterization of thyroxine-binding globulin in the carbohydrate-deficient glycoprotein syndrome type I. The Journal of Clinical Endocrinology \& Metabolism 80(12), 3744-3749 (1995)

118. Ross, D.S.: Serum thyroid-stimulating hormone measurement for assessment of thyroid function and disease. Endocrinol. Metab. Clin. N. Am. 30(2), 245-264 (2001)

119. Gbormittah, F.O., et al.: Clusterin glycopeptide variant characterization reveals significant site-specific glycan changes in the plasma of clear cell renal cell carcinoma. J Proteome Res, (2015)
120. Kakisaka, T., et al.: Plasma proteomics of pancreatic cancer patients by multi-dimensional liquid chromatography and twodimensional difference gel electrophoresis (2D-DIGE): upregulation of leucine-rich alpha-2-glycoprotein in pancreatic cancer. J. Chromatogr. B 852(1), 257-267 (2007)

121. van Reeuwijk, J., et al.: POMT2 mutations cause $\alpha$-dystroglycan hypoglycosylation and Walker-Warburg syndrome. J. Med. Genet. 42(12), 907-912 (2005)

122. Qiu, Y., et al.: Plasma glycoprotein profiling for colorectal cancer biomarker identification by lectin glycoarray and lectin blot. J. Proteome Res. 7(4), 1693-1703 (2008)

123. Wang, J., et al.: Identification of kininogen-1 as a serum biomarker for the early detection of advanced colorectal adenoma and colorectal cancer. PLoS One 8, e70519 (2013)

124. Cheng, Z., et al.: Kallistatin, a new and reliable biomarker for the diagnosis of liver cirrhosis. Acta Pharmaceutica Sinica B, (2015)

125. Dieplinger, H., Dieplinger, B.: Afamin-A pleiotropic glycoprotein involved in various disease states. Clin. Chim. Acta 446, 105110 (2015)

126. Gilgunn, S., et al.: Aberrant PSA glycosylation - a sweet predictor of prostate cancer. Nature Reviews Urology 10(2), 99-107 (2013) 